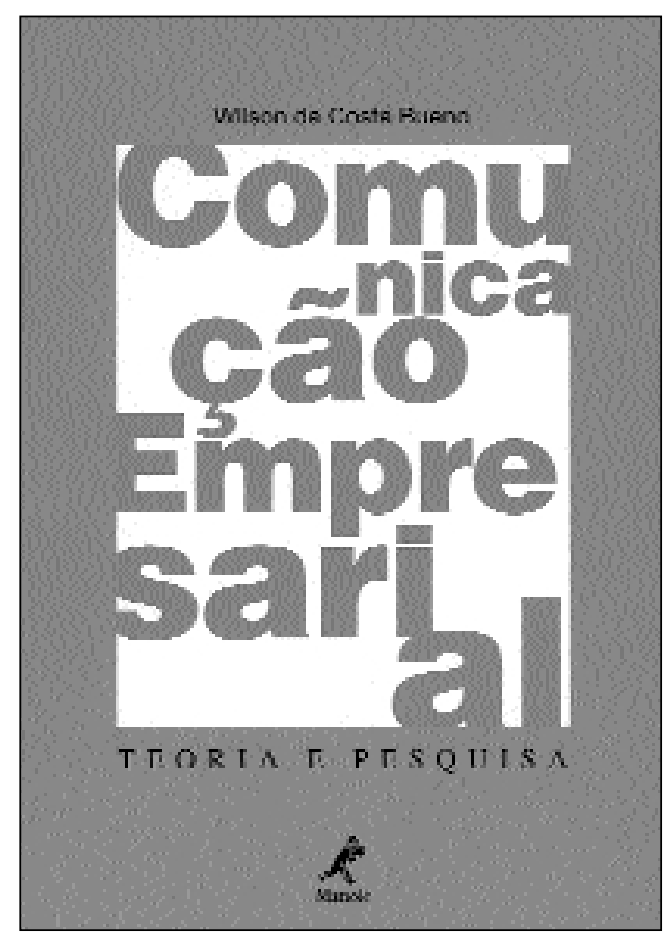

Wilson da Costa Bueno

Comunicação Empresarial Teoria e Pesquisa

Barueri:

Manole, 2003

370 páginas

Júlio César Barbosa

- Mestre em Comunicação e Mercado pela Faculdade Cásper Líbero

- Coordenador de Relações Públicas da Faculdade Cásper Líbero

- relacoespublicas@ facasper.com.br 


\section{Um olhar sobre o processo de comunicação}

'A comunicação empresarial tem requerido de empresas e de profissionais, uma conduta adequada aos novostempose aos novos desafios". A partir dessa proposição podemos iniciar a análise do livro de W ilson Bueno. 0 livro traz além de conceitos revisados, pesquisas aplicadas elaboradas pelo autor no intuito de entender todo o processo de comunicação empresarial nas empresas modernas, suas expectativas e perspectivas diante dos novos desafios da tecnologia de informação, da globalização e da administração de pessoas.

O autor, na primeira parte do livro, apresenta uma análise da teoria do processo de comunicação empresarial, propiciando uma reflexão sobre a mídia, suas funçõese sua importância, bem como enfatiza a gestão da comunicação na construção da imagem e identidade das organizações. Finaliza sua proposta discutindo o papel social das organizações, sua relação com o terceiro setor e a responsabilidade social. É preciso reforçar que esses dois tópicos, acima relacionados, são hoje o mote central de muitas discussões dentro e fora das organizações, buscando um novo paradigma de atuação para as mesmas, que vai além da máscara, da superficialidade ou do assistencial ismo. Em particular, vale ressaltar o capítulo em que avalia a comunicação como espelho das culturas empresariais e ressalta o valor da comunicação e de sua evolução de mero acessório para assumir uma função relevante na política de negócios da empresa, tentando estabelecer os principais aspectos dessa trajetória evolutiva.

A segunda parte do livro referenda a primeira, quando traz pesquisas aplicadas, comprovações, buscando em diferentes tipos de organização, traçar paralelos conceituais e práticos. 0 mais interessante nesse contexto éque, dentro da lógica de construção do texto, a organização ainda não entende ou dispõe de todo o instrumental da comunicação para a sua própria atuação. Outro ponto a salientar a favor da obra éque a aplicação e a utilização de pesquisas pelas empresas éhoje um diferencial para a gestão estratégica de comunicação.

Outra afirmação importante do autor éque a comunicação empresarial deixa de ser relegada àcondição de instrumento puro e simples, para ser entendida como um elemento de gestão empresarial capaz, por sua eficiência e efetividade, de mudar os rumos da organização. Ela deixa o patamar do fazer para ser entendida como elemento do saber. Caberáà comunicação empresarial um papel definitivo na consolidação da imagem institucional. 
A comunica o empresarial passa, ent 0 , por uma reciclagem em sua orienta o b si$\mathrm{ca}$, alargando seus horizontes e sendo melhor compreendida pelos dirigentes das organiza esn os pelosresultadosqueapresenta, mastamb m pela sua capacidade de gerar relacionamentos. A comunica o empresarial ganha espa o como uma filosofia de gest o estrat gica, como modelo de integra o esinergia. Portanto, temos um novo paradigma que afeta sobremaneira o modus operandi da pr pria forma de administra 0 .

0 que se observa muito profundamente no livro a inten o do autor em determinar, em primeira inst ncia, a import ncia da pesquisa por sua abrang ncia, valor eresultado diante de conflitos e impasses; dos relacionamentos como forma de manuten-

0 do status quo adquirido pela organiza 0 e da necessidade de perceber em profundidade pela organiza o seu discurso e planejar de maneira sin rgica, sist mica e eficaz, para assim determinar o grau de participa o social que a organiza o ter . Salienta tamb $m$ a quest 0 da comunica o interna e sua interface com a identidade da empresa/ organiza 0 .

Wilson Bueno faz um trabal ho extremamente conciso e organizado, criando uma I gica para a apresenta o das id ias, sobre as quais demonstra total dom nio. Nos d , de maneira assertiva - principalmente, aos professores - um material de primeira qualidade para o ensino da gradua 0 .

A relev ncia est presente quando podemos, pelas pesquisas apresentadas, visualizar de maneira clara um panorama da realidade empresarial brasileira, do ponto de vista da comunica 0 . Em especial quando cita o caso Petrobr $s$, no qual analisa a quest 0 da identidade corporativa e sua import ncia social. Fica claro o cuidado que devemos ter com as escolhas da organiza o no processo de tomada de decis 0 , bem como a import ncia dos $p$ blicos no contexto organizacional, seu poder de interfe$r$ ncia e sua capacidade de manifesta o positiva e negativa.

A terceira e Itima parte do livro traz uma cataloga o de obras e fontes de refer ncia sobre comunica o empresarial, na qual indica desde entidades at obras publicadas, passando por revistas e sites nacionais e estrangeiros. Este cap tulo de extrema validade por se tratar de criteriosa avalia 0 , com explica o detalhada da fun o e da forma de contato.

A leitura da obra nos traz a certeza de qu o essencial a comunica o para as organiza es, de seu papel como agente aglutinador, como o liame necess rio manuteno da organiza o como um sistema nico de informa o e de conhecimento. Talvez fosse apenas necess rio dentro desse contexto ampliar maisainda a discuss 0 , quem sabe apenas no sentido sem ntico de abordar $n$ o mais como comunica o empresarial, mas denomin -la, em definitivo, Comunica o Organizacional, assim justificando sua amplitude, magnitude, import ncia eseu grau de contribui 0 srela essociais nas organiza es modernas. 